\title{
Airport concrete pavement design by environmental and double dual tandem gear loadings
}

1 Jun-Hyeok Lee BEng

Graduate student, Department of Civil Engineering, Inha University, Incheon, South Korea

2 Yeon-Tae Kim MEng

Research Specialist, Korea Institute of Civil Engineering and Building Technology, Goyang-si, South Korea

3 Sereyvattana Tonn MEng Engineer, Civil Business Division, Daelim Industrial Co., Ltd, Seoul, South Korea

\section{Nam-Hyun Cho PhD}

Senior Researcher, Airport Research Institute, Incheon International Airport, Incheon, South Korea

5 Jin-Hoon Jeong PhD

Professor, Department of Civil Engineering, Inha University, Incheon South Korea (corresponding author: jhj@inha.ac.kr)
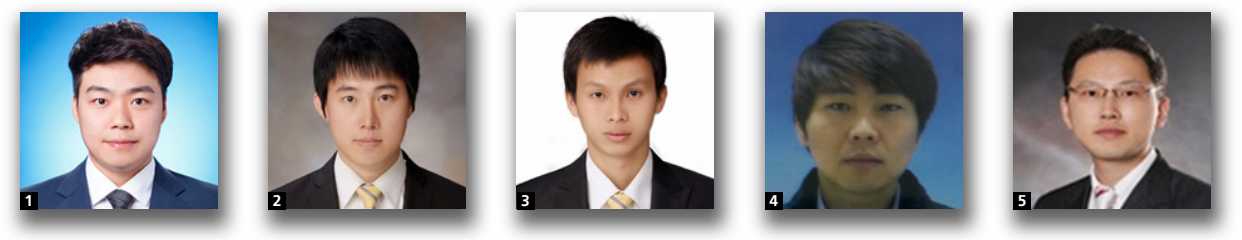

A method for designing an airport concrete pavement (ACP) that can withstand environmental loads as well as traffic loads is presented. Information on ACPs for which double dual tandem landing gears were used for design aircrafts was collected and the stresses induced on the slabs when environmental loads and traffic loads were simultaneously applied were predicted with the finite-element analysis program FeaFaa. In addition, a maximum tensile stress regression model of ACP slabs was developed using the statistical analysis program SPSS. When environmental and traffic loads were simultaneously applied, the maximum tensile stress obtained with the finite-element method was significantly different from that obtained using Westergaard's equation of edge loading only in traffic loads. Therefore, the fatigue model in the US Federal Aviation Administration's AC 150/5320-6E design method was corrected to be appropriate for this study. Using the stress regression model developed in this study and the corrected fatigue model, the thickness and joint spacing of existing ACP slabs were redesigned and compared with existing airport pavements. Previously, only the thickness of a slab was designed and the joint spacing was empirically determined. However, from the results of this study, a slab's thickness and joint spacing can be designed mechanistically.

\section{Notation}

$A, B, C, D$

$a$

$a_{1}, a_{2}, a_{3}, a_{4}$

$E_{\mathrm{c}}$

$F_{\text {cal }}$

$F_{\mathrm{s}}^{\prime}$

$f\left(F_{\text {cal }}\right)$

$h$

$h_{\text {calculated }}$

$h_{\text {existing }}$

$k$

$l$

$P$

$\mathrm{RH}_{\mathrm{LM}}$

$T C_{\mathrm{LM}}$ coefficients of temperature difference

radius of contact area $(\mathrm{mm})$

coefficients of shrinkage model determined by coarse aggregate type

elastic modulus of concrete (MPa)

stress scaling factor

stabilised base compensation factor

function used to obtain the stress scaling factor

slab thickness $(\mathrm{mm})$

calculated slab thickness $(\mathrm{mm})$

actual slab thickness (mm)

composite modulus of subgrade reaction $\left(\mathrm{MN} / \mathrm{m}^{3}\right)$

radius of relative stiffness $(\mathrm{mm})$

gear loading $(\mathrm{t})$

minimum monthly average relative humidity

maximum monthly average daily temperature

difference $\left({ }^{\circ} \mathrm{C}\right)$

age of concrete (d)

\begin{tabular}{|c|c|}
\hline$V / S$ & shape ratio (volume/surface) (mm) \\
\hline$z$ & $\begin{array}{l}\text { distance from middle depth of slap to a } \\
\text { specific depth (positive, upward; negative, } \\
\text { downward) (mm) }\end{array}$ \\
\hline$\alpha_{\mathrm{c}}$ & coefficient of thermal expansion of concrete $\left(/{ }^{\circ} \mathrm{C}\right.$ \\
\hline$\Delta T$ & $\begin{array}{l}\text { temperature difference between a specific deptl } \\
\text { and middle depth of slab }\left({ }^{\circ} \mathrm{C}\right)\end{array}$ \\
\hline$\Delta T_{\text {eq }}$ & $\begin{array}{l}\text { equivalent linear temperature difference (ELTD) } \\
\text { between top and bottom of slab }\left({ }^{\circ} \mathrm{C}\right)\end{array}$ \\
\hline$\Delta T_{\mathrm{sh}}$ & differential shrinkage ELTD $\left({ }^{\circ} \mathrm{C}\right)$ \\
\hline$\Delta T_{\text {sh-re }}$ & $\begin{array}{l}\text { differential shrinkage ELTD considering stress } \\
\text { relaxation }\left({ }^{\circ} \mathrm{C}\right)\end{array}$ \\
\hline$\Delta T_{\text {total }}$ & total ELTD $\left({ }^{\circ} \mathrm{C}\right)$ \\
\hline$\varepsilon_{\mathrm{sh}}$ & shrinkage of concrete \\
\hline$\varepsilon_{\mathrm{ush}}$ & ultimate shrinkage of concrete \\
\hline$\mu$ & Poisson's ratio of concrete \\
\hline$\sigma_{\mathrm{e}}$ & Westergaard's edge stress of concrete slab (MPa) \\
\hline$\sigma_{\max (e n v i r o n m e n t)}$ & $\begin{array}{l}\text { maximum tensile stress due to the } \\
\text { environmental loading (MPa) }\end{array}$ \\
\hline
\end{tabular}

$V / S \quad$ shape ratio (volume/surface) (mm)

distance from middle depth of slap to a specific depth (positive, upward; negative, coefficient of thermal expansion of concrete $\left(/{ }^{\circ} \mathrm{C}\right)$ temperature difference between a specific depth and middle depth of slab $\left({ }^{\circ} \mathrm{C}\right)$ between top and bottom of slab $\left({ }^{\circ} \mathrm{C}\right)$ ( $\left({ }^{\circ} \mathrm{C}\right)$ relaxation $\left({ }^{\circ} \mathrm{C}\right)$ total ELTD $\left({ }^{\circ} \mathrm{C}\right)$ shrinkage of concrete age of con Westergaard's edge stress of concrete slab (MPa) environmental loading (MPa) 


$\begin{array}{ll}\sigma_{\max (\text { traffic) }} & \begin{array}{l}\text { maximum tensile stress due to double dual } \\ \text { tandem (DDT) gear loading (MPa) }\end{array} \\ \sigma_{\max (\text { total })} & \begin{array}{l}\text { maximum tensile stress due to DDT gear } \\ \text { loading and environmental loading (MPa) } \\ \text { stress relaxation ratio }\end{array} \\ \phi(t) & \end{array}$

\section{Introduction}

The method of designing airport concrete pavements (ACPs) is changing from a conventional empirical method to a mechanistic method. However, owing to limitations in data that reflect the diversity of damage mechanisms, a perfect mechanistic design method has yet to be developed and an empirical design method with a mechanistic concept partially centred on engineering logic and past experience is still used.

The US Federal Aviation Administration's (FAA) AC 150/5320-6E design method (FAA, 2009) is a mechanisticempirical design method that calculates the maximum tensile stress that has occurred in an ACP slab due to aeroplane loads using the finite-element analysis (FEA) program FaarField. In addition, FaarField predicts the lifespan of a pavement using a fatigue model (FAA, 2009). However, this design method requires many input variables, including data on diverse aeroplane gears and material properties of the pavement layers. It also has the disadvantages of failing to consider environmental loads related to climatic conditions and to a designed pavement joint spacing.

Previous researchers have concluded that large stress occurs due to environmental loads within a concrete slab (Kim, 2007) and that this stress cannot be ignored. However, existing design methods fail to consider environmental loads. The environmental loads on an ACP can be differentiated into different temperature and moisture loads due to temperature and moisture distributions within the slab, respectively (Park et al., 2015). Research to quantify the impact of environmental loads aimed at a mechanistically designed ACP was recently reported by Liu (2015).

With respect to ACPs designed for double dual tandem (DDT) landing gears on aircraft (one of the popular aeroplane gears), an FEA program was used in this study to calculate stresses from traffic loads and environmental loads and the stresses that occur when these two kinds of loads act simultaneously. In addition, a regression model was developed using the statistical analysis program SPSS. The stress calculated using the developed model is different from that using the existing stress calculation method, which uses only traffic loads, because the effect of environmental loads is also considered in the proposed model. Owing to the different stresses caused by these loads, the design lifespans predicted by the proposed model and the existing fatigue model without any modification were different. The existing fatigue model thus needs to be corrected. In the current study, the fatigue model in the AC
150/5320-6E design method (FAA, 2009) was corrected using a method presented by Brill (2010) and it was found that the slab thickness satisfied the design lifespan. Furthermore, slab thicknesses calculated using the corrected method were compared with the thickness of actual ACP slabs. This paper also presents a method for determining optimal slab thickness according to the joint spacing of the ACP.

\section{Development of the maximum tensile stress prediction model}

The stresses due to environmental and gear loads occurring in concrete pavements at Incheon international airport, Muan international airport, Cheongju international airport and Sacheon airport, which were designed for DDT gears, were calculated. Analyses were conducted by inputting the design information for each airport into FeaFaa, a FEA program developed by the FAA. Figure 1 shows the locations of the studied airports and relevant information for each is given in Table 1.

\subsection{Models of environmental loads}

Concrete slabs undergo curling and warping due to the heterogeneous distribution of internal temperature and moisture. Such twisting is confined by friction between the sub-bases, slab weight and dowel and tie bars, which triggers stress within the slab. However, it is difficult to use the actual slab

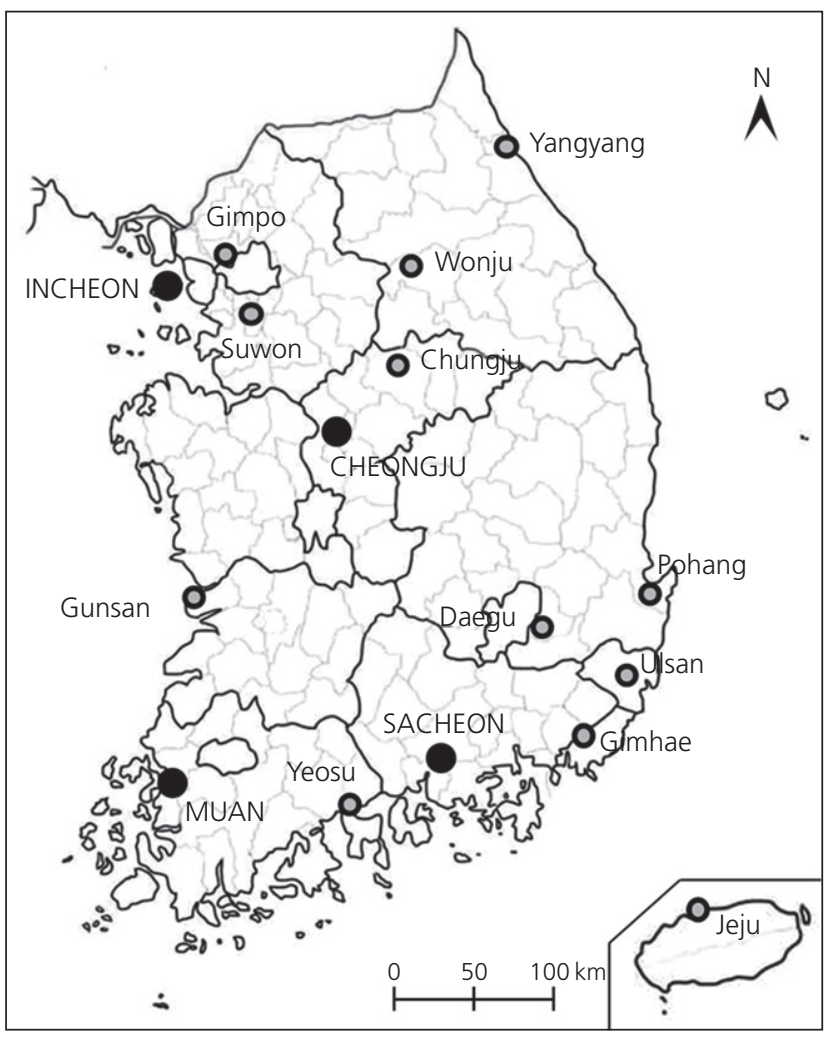

Figure 1. Locations of airports in Korea 
Table 1. Information on ACPs designed for DDT gear loading at the considered airports in Korea

\begin{tabular}{|c|c|c|c|c|}
\hline & Incheon & Muan & Cheongju & Sacheon \\
\hline Design standard & AC 150/5320-6D & AC $150 / 5320-6 D$ & AC $150 / 5320-6 D$ & AC 150/5320-6E \\
\hline Design aircraft & B747-400S & B747-400 & B747-400 & B747-400 \\
\hline Maximum take-off weight: $t$ & 492 & 400 & 400 & 400 \\
\hline Design traffic volume: times/year & 154338 & 30306 & 22176 & 4491 \\
\hline Subgrade reaction: pci & 200 & 160 & 250 & 180 \\
\hline \multicolumn{5}{|l|}{ Thickness of pavement layers: mm } \\
\hline Slab & 500 & 400 & 400 & 380 \\
\hline AC & 50 & 50 & - & - \\
\hline CTB & 150 & 150 & - & 150 \\
\hline Crushed stone sub-base & 150 (anti-frost layer) & 160 & 350 & 200 \\
\hline \multicolumn{5}{|l|}{ Joint type } \\
\hline Contraction joint & Dowel bar & Dowel bar & Dowel bar & Dowel bar \\
\hline Construction joint & Key & Key & Dowel bar & Dowel bar \\
\hline $\begin{array}{l}\text { Joint spacing: } m \\
\text { Dowel bar }\end{array}$ & \multicolumn{4}{|c|}{ Dowel bar } \\
\hline Diameter: $\mathrm{mm}$ & 40 & 40 & 40 & 40 \\
\hline Length: mm & 510 & 510 & 510 & 510 \\
\hline Spacing: mm & 460 & 460 & 460 & 460 \\
\hline
\end{tabular}

pci, Ib/in ${ }^{3}\left(27 \cdot 8 \mathrm{~g} / \mathrm{cm}^{3}\right) ; A C$, asphalt concrete; CTB, cement treated base

temperature as an input to structural analysis because of its non-linearity with depth.

Mohamed and Hansen (1997) developed a model to convert the non-linear temperature distribution within a slab into a linear temperature distribution with mechanistic equivalence. The temperature difference between a certain depth and the middle depth of a slab is expressed in a third-order polynomial of distance $(z)$ from the middle depth of the slab to a certain depth, as given by

1. $\Delta T=A+B z+C z^{2}+D z^{3}$

where $\Delta T$ is the temperature difference between a specific depth and the middle depth of the slab $\left({ }^{\circ} \mathrm{C}\right), z$ is the distance from the middle depth to a specific depth (positive, upward; negative, downward) (mm) and $A, B, C$ and $D$ are coefficients of temperature difference.

Using the coefficients $B$ and $D$ in Equation 1, the equivalent linear temperature difference (ELTD) between the slab top and bottom $\left(\Delta T_{\mathrm{eq}}\right)$, which has mechanistic characteristics equivalent to a non-linear temperature distribution according to depth, is expressed as

2. $\Delta T_{\text {eq }}=-12\left(\frac{B h}{12}+\frac{D h^{3}}{80}\right)$

where $h$ is the slab thickness (mm).

Warping triggers a stress in the slab by the same action as curling, except for the fact that warping occurs due to a change in moisture according to the depth. Many models have been developed to predict the drying shrinkage of concrete due to moisture evaporation (e.g. Bazant and Boweja, 1995; Gardner, 2004; Videla et al., 2008; Yang et al., 2004). In the current study, the drying shrinkage of concrete was predicted using the model proposed by Yang et al. (2004), which is given by

3. $\varepsilon_{\mathrm{sh}}=\frac{a_{1} t}{a_{2}+t}\left[1+a_{3} \mathrm{e}^{\left(-a_{4} V / S\right)}\right]$

where $\varepsilon_{\mathrm{sh}}$ is the concrete shrinkage, $t$ is the age of the concrete (d), $V / S$ is the shape ratio of the concrete (volume/surface, in $\mathrm{mm})$ and $a_{1}-a_{4}$ are coefficients of the shrinkage model determined by the type of coarse aggregate.

Bazant and Panula (1978) proposed a model to predict the strain in concrete due to drying shrinkage according to the relative humidity of the atmosphere. This model is given by

4. $\varepsilon_{\mathrm{sh}}=\varepsilon_{\mathrm{ush}}\left(1-\mathrm{RH}^{3}\right)$

where $\varepsilon_{\text {ush }}$ is the ultimate shrinkage of concrete and $\mathrm{RH}$ is the ambient relative humidity.

Jeong et al. (2012) combined the models of Yang et al. (2004) and Bazant and Panula (1978) to reflect the 60\% relative humidity used in the experiment on drying shrinkage carried out by Yang et al. (2004). They thereby developed the following model to predict drying shrinkage considering the effects of atmospheric relative humidity.

5. $\varepsilon_{\mathrm{sh}}=\frac{a_{1} t}{a_{2}+t}\left(1+a_{3} \mathrm{e}^{\left(-a_{4} V / S\right)}\right) \times \frac{1-R H^{3}}{1-0 \cdot 6^{3}}$

In addition, by measuring slab deformation due to temperature and moisture variations in the field, Jeong et al. (2012) 
proposed a model that links concrete drying contraction to temperature and transforms it into an equivalent ELTD having the same effect as the actual shrinkage. The differential shrinkage ELTD, $\Delta T_{\mathrm{sh}}\left({ }^{\circ} \mathrm{C}\right)$, is given by

6. $\Delta T_{\mathrm{sh}}=\frac{a h}{\alpha_{\mathrm{c}}} \varepsilon_{\mathrm{sh}}$

in which $a$ is a coefficient of the differential shrinkage ELTD model and $\alpha_{\mathrm{c}}$ is the coefficient of thermal expansion of concrete $\left({ }^{\circ} \mathrm{C}\right)$.

In another study, Park et al. (2009) measured the strain according to the drying shrinkage of a free-drying cylindrical concrete sample and a free-drying prismatic concrete sample. The measured strain was substituted into the elastic stress and residual stress prediction model proposed in previous research (Hossain and Weiss, 2004) to derive the difference in stress relaxation. Then, using the ratio of relaxed stress to elastic stress, the model of differential shrinkage ELTD that considers stress relaxation was given as

7. $\Delta T_{\text {sh-re }}=\Delta T_{\text {sh }}(1-\phi)$

where $\Delta T_{\text {sh-re }}$ is the differential shrinkage ELTD considering stress relaxation $\left({ }^{\circ} \mathrm{C}\right)$ and $\phi(t)$ is the stress relaxation ratio $(\phi=A / t+B ; A=-1 \cdot 775, B=0 \cdot 6)$.

Park et al. (2015) combined the ELTD (Equation 2) and the differential shrinkage ELTD (in which stress relaxation is considered) (Equation 7) into the total ELTD $\left(\Delta T_{\text {total }}\right)$ and then defined this as the environmental load on an ACP.

\section{8. $\Delta T_{\text {total }}=\Delta T_{\text {eq }}+\Delta T_{\text {sh-re }}$}

In order readily to calculate the total ELTD between the top and bottom of an ACP slab in different regions, Park et al. (2013) developed a regression model (Equation 9) in which the maximum monthly average daily temperature difference $\left(T C_{\mathrm{LM}}\right)$, the minimum monthly average relative humidity $\left(\mathrm{RH}_{\mathrm{LM}}\right)$ and the slab thickness $(h)$ were used as independent variables.

$$
\text { 9. } \Delta T_{\text {total }}=-2 \cdot 636(h)^{0.772}\left(T C_{\mathrm{LM}}\right)^{0.105}\left(\mathrm{RH}_{\mathrm{LM}}\right)^{-0.672}
$$

\subsection{Model of maximum tensile stress under environmental loads}

In order to calculate the maximum tensile stress in a slab due to environmental loads, information on meteorological conditions and concrete pavement slab thicknesses of 17 private and military airports were collected (Kim, 2014). By inputting the collected data into Equation 9, the total ELTD between the top and bottom of each ACP slab was calculated. Figure 2 shows the total ELTD of each ACP according to the slab thickness. The figure shows that an increase in slab thickness resulted in an increase in total ELTD. Moreover, differences were found between regions: the total ELTD was $20 \cdot 2^{\circ} \mathrm{C}$ in Gunsan and $26 \cdot 3^{\circ} \mathrm{C}$ in Chungju for a slab thickness of $500 \mathrm{~mm}$.

As input variables, the FEA program FeaFaa utilises different types of design aircrafts, the thickness of each pavement layer, elastic modulus, Poisson's ratio and joint spacing, the size and location of gear load, the temperature difference between the top and bottom of the slab, the coefficient of thermal expansion of the slab and material properties of the load transfer device. With this in mind, in this study, the factors predicted to affect the stress of ACP slabs were

- joint spacing

- total ELTD between the top and bottom of the slab

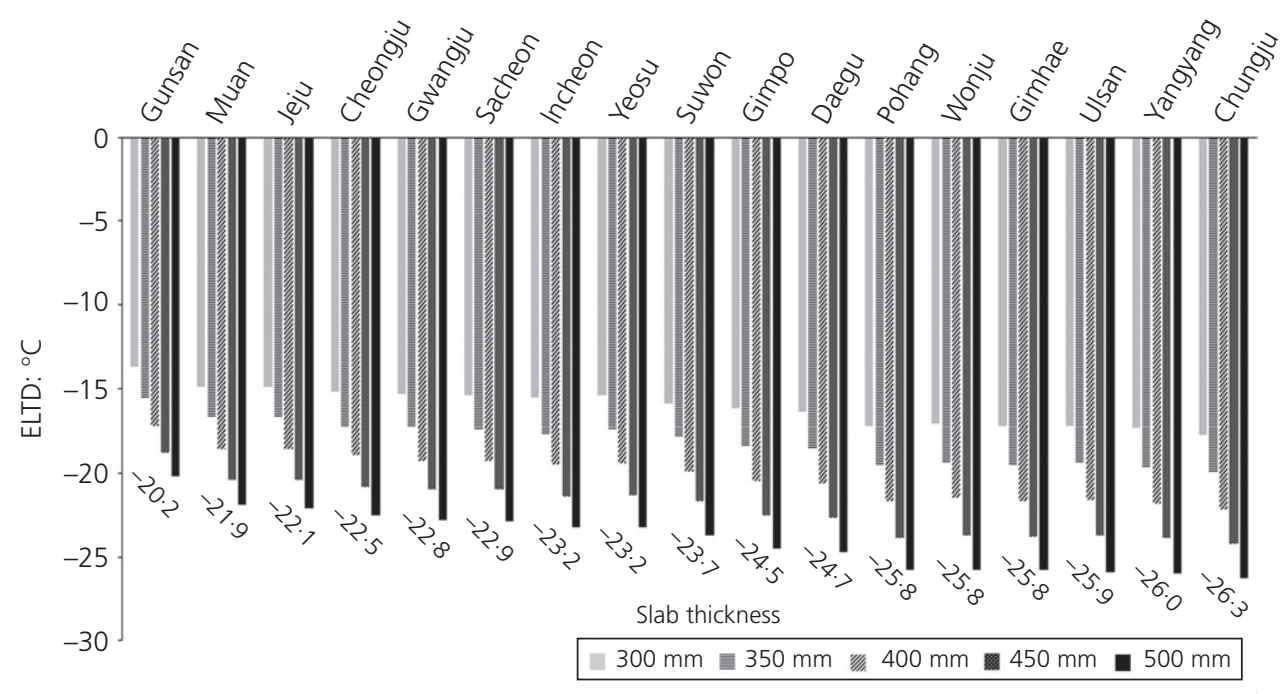

Figure 2. Regional total ELTD according to slab thickness 
magnitude of gear load

slab thickness

modulus of elasticity of the slab

- Poisson's ratio of the slab

composite modulus of subgrade reaction under the slab bottom

modulus of elasticity of the dowel bar.

It was assumed that only the modulus of elasticity of the slab has an effect on the stress among those factors affecting the pavement layers. Furthermore, the gear load was excluded from the sensitivity analysis as it was not included in the environmental loads.

As shown in Table 2, the upper and lower limits of the different parametric factors were determined and the middle values were assumed as reference values to analyse the sensitivity of the maximum tensile stress of the slab. All the factors were fixed on the reference value and, to investigate changes in the slab maximum tensile stress, a factor whose sensitivity was desired to be known was only changed from the lower limit to the upper limit.

According to the results of the sensitivity analysis shown in Table 3, the joint spacing was observed to have the greatest effect on changes in stress due to environmental loads, followed by the total ELTD and then the composite modulus of the subgrade reaction. For the elastic modulus of the slab, Poisson's ratio of the slab and the elastic modulus of the dowel bar, the change in magnitude of maximum tensile stress as a result of changing the factor from the lower limit to the upper limit was less than $5 \%(0.06 \mathrm{MPa})$ of the reference stress $(1.21 \mathrm{MPa})$ calculated with the reference values of each factor. Therefore, it was concluded that their effects on stress were relatively small and they were excluded from the identified influential factors.

Multiple regression analysis was then conducted with the influential factors selected through the sensitivity analysis as independent variables and the maximum tensile stress of the slab as the dependent variable to develop the regression model

$$
\text { 10. } \begin{aligned}
\log \sigma_{\max (\text { environment })=} & 0.448+0 \cdot 248 \mathrm{JS}+0.015\left|\Delta T_{\text {total }}\right| \\
& -0.003 k
\end{aligned}
$$

where $\sigma_{\max (e n v i r o n m e n t)}$ is the maximum tensile stress due to environmental loading (MPa), JS is the joint spacing (m), $k$ is the composite modulus of the subgrade reaction $\left(\mathrm{MN} / \mathrm{m}^{3}\right)$ and $\Delta T_{\text {total }}$ is the total ELTD $\left({ }^{\circ} \mathrm{C}\right)$.

A larger maximum tensile stress was obtained when the joint spacing and the absolute value of the total ELTD were larger and the composite modulus of the subgrade reaction was held at a smaller value. The location of the maximum tensile stress that occurred due to environmental loads was identified using the program Tecplot 360. Based on the result shown in Figure 3, the maximum tensile stress occurred at the top of the middle part of the slab (Kim, 2014).

\begin{tabular}{|c|c|c|c|c|}
\hline Factor & $\begin{array}{l}\text { Lower } \\
\text { limit }\end{array}$ & $\begin{array}{l}\text { Reference } \\
\text { value }\end{array}$ & $\begin{array}{l}\text { Higher } \\
\text { limit }\end{array}$ & Reason for range of values \\
\hline Joint spacing: $m$ & $3 \cdot 8$ & $5 \cdot 7$ & $7 \cdot 6$ & Range of joint spacing of worldwide airport pavements \\
\hline Gear loading: $t$ & 330 & 412 & 494 & Range of maximum take-off loading of DDT-geared aeroplane \\
\hline Slab thickness: mm & 200 & 350 & 500 & Range of slab thickness of worldwide airport pavements \\
\hline $\begin{array}{l}\text { Composite modulus of } \\
\text { subgrade reaction: } \mathrm{MN} / \mathrm{m}^{3}\end{array}$ & $97 \cdot 56$ & $121 \cdot 47$ & $145 \cdot 38$ & $\begin{array}{l}\text { Converted by nomograph of bearing capacity from } \\
\text { subgrade reaction }\end{array}$ \\
\hline Elastic modulus of slab: GPa & 22 & 28 & 34 & Ordinary elastic modulus of concrete slab $\pm 20 \%$ \\
\hline Poisson's ratio of slab & $0 \cdot 16$ & $0 \cdot 2$ & 0.24 & Ordinary Poisson's ratio of concrete slab $\pm 20 \%$ \\
\hline Elastic modulus of dowel bar: GPa & 160 & 200 & 240 & Ordinary elastic modulus of dowel bar $\pm 20 \%$ \\
\hline
\end{tabular}

Table 2. Factors influencing the stress of pavement slab

Table 3. Sensitivity of maximum tensile stress under environmental load

\begin{tabular}{llc}
$\begin{array}{l}\text { Ranking by } \\
\text { sensitivity }\end{array}$ & Factor & $\begin{array}{c}\text { Difference in stress due to maximum } \\
\text { and minimum values of factor: } \mathbf{M P a}\end{array}$ \\
\hline 1 & Joint spacing & $1 \cdot 09$ \\
2 & ELTD & $0 \cdot 39$ \\
3 & Composite modulus of subgrade reaction & $0 \cdot 13$ \\
4 & Elastic modulus of slab & 0.05 \\
5 & Poisson's ratio of slab & 0.02 \\
6 & Dowel elastic modulus & 0.01
\end{tabular}




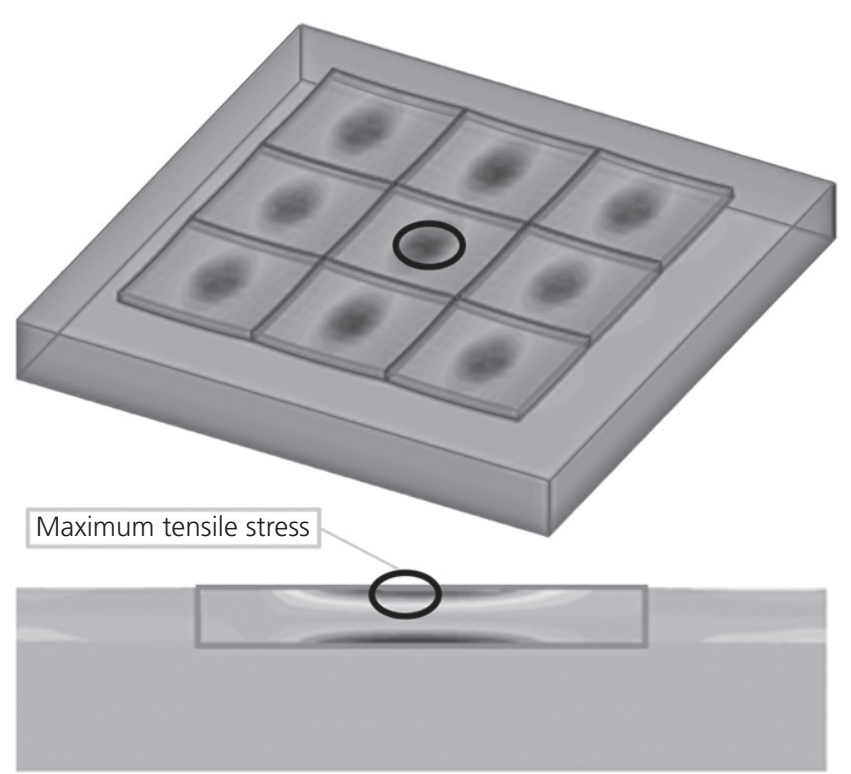

Figure 3. Location of maximum tensile stress caused by environmental loading

\subsection{Model of maximum tensile stress under traffic loads}

The earlier version of the FAA standards for airport pavement design and evaluation, AC 150/5320-6D (FAA, 1995), uses Equation 11 - the equation of Westergaard's edge loading (Westergaard, 1948) - to calculate the maximum tensile stress that occurs when the gear load of a design aircraft is applied to the edge of an ACP slab.

$$
\begin{aligned}
\sigma_{\mathrm{e}}= & \frac{3(1+\mu)}{(3+\mu) \pi h^{2}}\left[\ln \left(\frac{E_{\mathrm{c}} \cdot h^{3}}{100 k a^{4}}\right)+1 \cdot 84-\frac{4 \mu}{3}\right. \\
& \left.+\frac{(1-\mu)}{2}+1 \cdot 18(1+2 \mu) \frac{a}{l}\right]
\end{aligned}
$$

Here, $\sigma_{\mathrm{e}}$ is Westergaard's edge stress of a concrete slab (MPa), $\mu$ is Poisson's ratio of the concrete, $E_{\mathrm{c}}$ is the elastic modulus of the concrete (MPa), $a$ is the radius of contact area $(\mathrm{mm})$ and $l$ is the radius of relative stiffness $(\mathrm{mm})$.

DDT gear is relevant only to B747 aeroplanes and thus only one main gear between the two main gears of the aeroplane is placed on a slab when the joint spacing is less than $5 \mathrm{~m}$ (Figure 4). When load was applied to the edge of a slab, as shown in Figure 5(a), the FeaFaa program predicted the maximum tensile stress to occur at the bottom of the slab in the same location as that of the result of the equation of Westergaard's edge loading. However, when the joint spacing was $5 \mathrm{~m}$ or greater, as shown in Figure 5(b), when the two main gears were applied to the corners of the slab symmetrically, the maximum tensile stress occurred at the slab bottom of each gear's location.

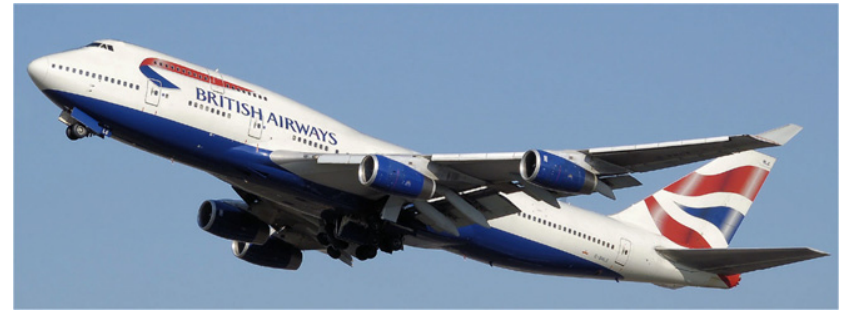

(a)
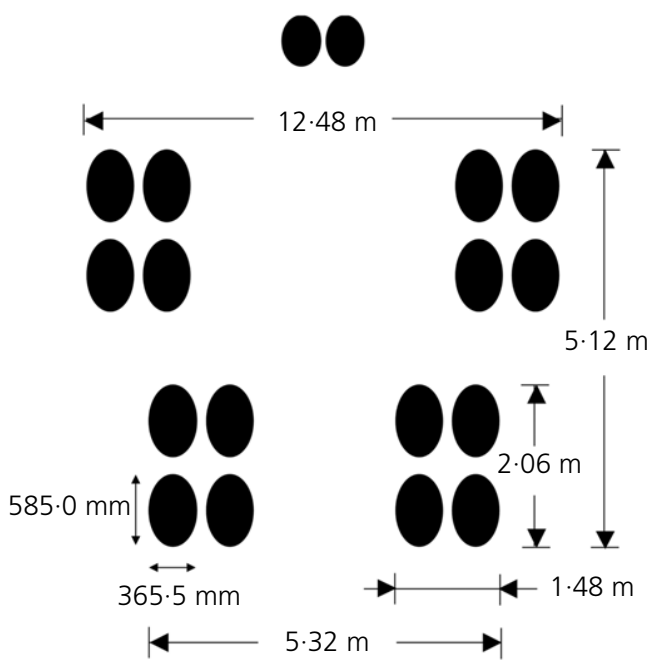

(b)

Figure 4. (a) B747 with DDT gear. (b) Footprint of DDT gear

The sensitivity of the maximum tensile stress of ACP slabs was analysed according to the modulus of elasticity, magnitude of gear load, slab thickness, Poisson's ratio of the slab, composite modulus of the subgrade reaction, modulus of elasticity of the dowel bar and joint spacing. As shown in Table 4, the greatest change in maximum tensile stress calculated by changing each factor from its lower to upper limit value was due to slab thickness, followed by gear loading, joint spacing and the composite modulus of subgrade reaction. The slab's modulus of elasticity and Poisson's ratio and the modulus elasticity of the dowel bar were excluded from the influential factors based on the fact that these factors produced a change in maximum tensile stress smaller than $5 \%(0.08 \mathrm{MPa})$ of the reference stress.

The remaining influential factors and the maximum tensile stress caused by DDT gear loading were then used as independent and dependent variables, respectively, in a multiple regression analysis. In relation to the two cases where one DDT main gear was loaded or two DDT main gears were loaded within a single slab according to the joint spacing, the following stress regression equations were developed using the DDT traffic loads. 
When the joint spacing is less than $5 \mathrm{~m}$

$12 \mathrm{a}$

$$
\begin{aligned}
\log \sigma_{\max (\text { traffic })=} & 0.949-1.224 \log h-1.453 \log \mathrm{JS} \\
& +0.764 \log P+0.055 \log k
\end{aligned}
$$

and when the joint spacing is $5 \mathrm{~m}$ or greater

$12 b$.

$$
\begin{aligned}
\log \sigma_{\max (\text { traffic })=} & -0.495+0.836 \log P-1.111 \log h \\
& +0.139 \log k+0.067 \log l
\end{aligned}
$$
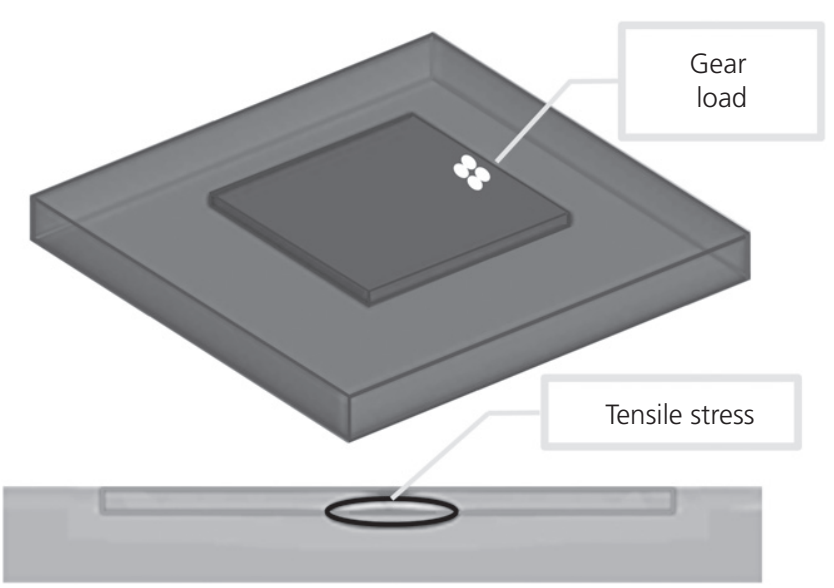

(a)

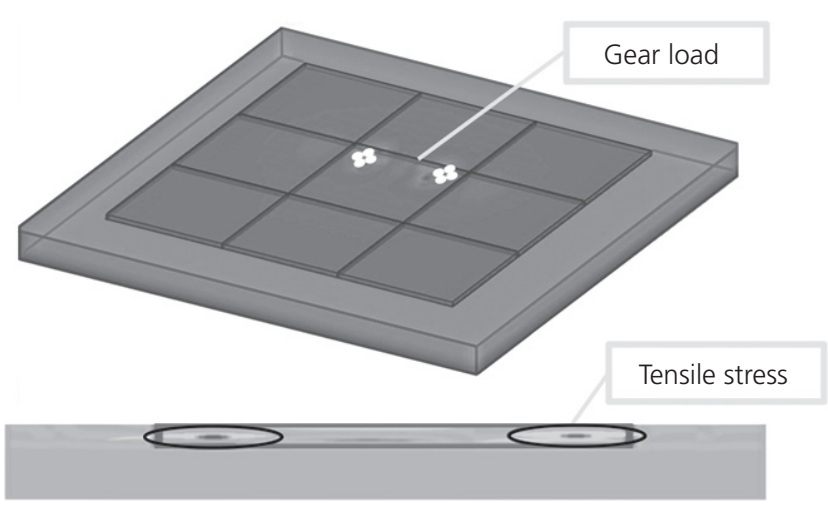

(b)

Figure 5. Location of the maximum tensile stress caused by DDT gear loading where $\sigma_{\max (t r a f f i c}$ is the maximum tensile stress due to DDT gear loading $(\mathrm{MPa})$ and $P$ is the gear loading (in tons; 1 ton $=$ 0.91 metric tonne).

\subsection{Model of maximum tensile stress under simultaneous environmental and traffic loads}

The existing design method for ACPs fails to consider the environmental loads and the stress generated by simply applying gear loads to the centre of the slab edge (FAA, 2009). In the current study, a regression model of the maximum tensile stress occurring in a slab when environmental loads and DDT gear loads are simultaneously applied $\left(\sigma_{\max (t o t a l)}\right)$ was developed. The regression model of Equation 13 was developed for maximum tensile stresses by traffic and environmental loads acting as independent variables and acting simultaneously as the dependent variable.

\section{3. $\log \sigma_{\max (\text { total })}=0 \cdot 334+0 \cdot 208 \cdot \log \sigma_{\max (\text { environment })}$ $+0.408 \cdot \log \sigma_{\max (\text { traffic })}$}

\section{Correction of the fatigue model for ACP slabs}

Figure 6 shows a comparison of the stress-strength ratios calculated using Westergaard's edge loading equation as used in AC 150/5320-6D (FAA, 1995) and the stress regression model (Equation 13) for concrete pavement slabs at Incheon international airport, Muan international airport, Cheongju international airport and Sacheon airport. Here, the stress-strength ratio refers to the stress in the slab due to the load divided by the concrete flexural tensile strength (Yu, 2000); in this study it was assumed that the flexural tensile strength of the concrete was $4.9 \mathrm{MPa}$. The stress-strength ratios determined according to AC 150/5320-6D, which only considers traffic loads, were greater than the ratios obtained by the model proposed in this study when only traffic loads or only environmental loads were considered. However, the stress-strength ratio according to AC $150 / 5320-6 \mathrm{D}$ was smaller than that obtained by the current model when considering both traffic and environmental loads. The differences in the ratios are due to the differences in the stresses calculated using Westergaard's edge equation and those obtained from FEA.

Table 4. Sensitivity of maximum tensile stress under DDT gear loading

\begin{tabular}{llr}
$\begin{array}{l}\text { Ranking by } \\
\text { sensitivity }\end{array}$ & Factor & $\begin{array}{c}\text { Difference in stress due to maximum and } \\
\text { minimum values of factor: MPa }\end{array}$ \\
\hline 1 & Slab thickness & $1 \cdot 37$ \\
2 & Gear loading & $0 \cdot 59$ \\
3 & Joint spacing & $0 \cdot 35$ \\
4 & Composite modulus of subgrade reaction & $0 \cdot 16$ \\
5 & Elastic modulus of slab & 0.03 \\
6 & Poisson's ratio of slab & 0.01 \\
7 & Dowel elastic modulus & 0.01
\end{tabular}


Therefore, the maximum tensile stress predicted by the proposed model may not be applicable to the fatigue model of the existing design method because of the use of Westergaard's edge loading equation in the existing design method. By reviewing fatigue models developed by different researchers, a model appropriate for this study was selected and corrected so that the maximum tensile stress calculated by the proposed model could be used. The various fatigue models examined included the Portland cement association (PCA) model (Packard, 1974), the Corps of Engineers (CoE) modified Westergaard model (Rollings, 1989), the Darter model (Darter, 1990), the Rollings and Witczak model (Rollings and Witczak, 1990), the NCHRP 1-26 model (Thompson and Barenberg, 1992), the AC 150-5320-6D model (FAA, 1995) and the AC 150-5320-6E model (FAA, 2009) were examined. Figure 7 shows the number of allowable load repetitions. The number of allowable load repetitions changed according to the stress-strength ratio. A significant difference in the design lifespans predicted by the fatigue models was observed, notwithstanding the fact that the stress remained the same.

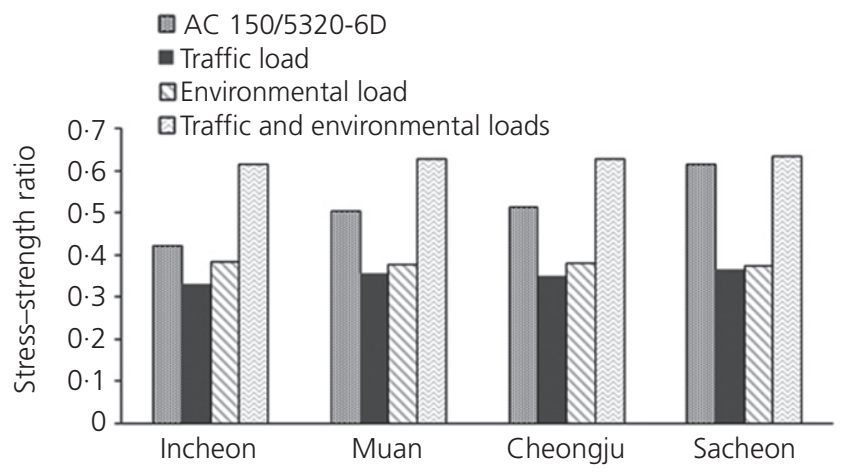

Figure 6. Comparison of stress-strength ratios calculated by the different stress models

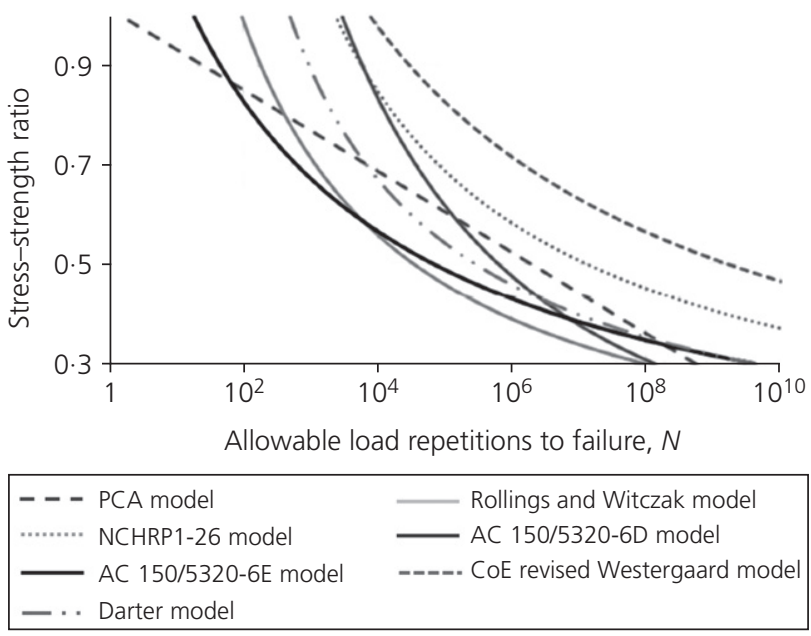

Figure 7. Comparison of stress-strength ratios predicted by different fatigue models
The fatigue models of AC 150/5320-6D to AC 150/5320-6E were selected because most Korean airports that use DDT design aircraft gears were designed with the FAA design method as the baseline. As the version of the design method changed from $\mathrm{AC}$ 150/5320-6D (FAA, 1995) to AC 150/5320-6E (FAA, 2009), the finite-element method was used to the calculate stress instead of Westergaard's edge loading equation. In addition, Equation 14, developed by analysing the results of full-scale experiments, is used as the fatigue model in AC 150/5320-6E (Brill, 2010).

14.

$$
\begin{aligned}
\frac{\mathrm{DF}}{F_{\mathrm{cal}}}= & \left\{\frac{F_{\mathrm{s}}^{\prime} b d}{[1-(\mathrm{SCI} / 100)](d-b)+F_{\mathrm{s}}^{\prime} b}\right\} \times \log C \\
& +\left\{\frac{[1-(\mathrm{SCI} / 100)](a d-b c)+F_{\mathrm{s}}^{\prime} b c}{[1-(\mathrm{SCI} / 100)](d-b)+F_{\mathrm{s}}^{\prime} b}\right\}
\end{aligned}
$$

In Equation 14, SCI is the structure condition index, DF is the design factor, $F_{\text {cal }}$ is the stress scaling factor, $F_{\text {cal }}$ is the stabilised base compensation factor and $a, b, c$ and $d$ are parameters. Table 5 shows the values of the variables used in the fatigue model.

The fatigue model of Equation 14 was originally developed using the stress-strength ratio calculated from Westergaard's edge loading equation. Therefore, it needed to be modified so that the tensile stress calculated using the finite-element method of AC 150/5320-6E can be applied. AC 150/5320-6E gives $1 \cdot 13$ as the fatigue model's stress scaling factor $\left(F_{\text {cal }}\right)$ derived using the method of least-squares (Equation 15). This is to ensure that the same slab thickness as that used in AC 150/5320-6D could be obtained.

$$
\text { 15. } f\left(F_{\text {cal }}\right)=\sum\left(h_{\text {calculated }}-h_{\text {existing }}\right)^{2}
$$

In Equation 15, $f\left(F_{\text {cal }}\right)$ is a function used to obtain the stress scaling factor, $h_{\text {calculated }}$ is the calculated slab thickness $(\mathrm{mm})$ and $h_{\text {existing }}$ is the actual slab thickness (mm).

To design a slab with the same thickness as that of the existing ACP and to account for stresses occurring as a result of simultaneous environmental and traffic loads, the fatigue model's stress scaling factor was revised. First, a stress scaling factor was assumed and substituted into the fatigue model of Equation 14. Then, the slab thicknesses of the studied airports (Incheon, Muan, Cheongju and Sacheon) were calculated using AC 150/5320-6E with a design lifespan of 20 years. The actual slab thickness of each airport was then substituted

Table 5. Values of the variables of the fatigue model of $A C$ 150/5320-6E (FAA, 2009)

\begin{tabular}{cccccc}
$\boldsymbol{F}_{\text {cal }}$ & $\boldsymbol{F}_{\mathbf{s}}^{\prime}$ & $\boldsymbol{a}$ & $\boldsymbol{b}$ & $\boldsymbol{c}$ & $\boldsymbol{d}$ \\
\hline 1.13 & 1.0 & 0.5878 & 0.2523 & 0.7409 & 0.2465 \\
\hline
\end{tabular}


into Equation 15 to derive the square of the difference between slab thicknesses and, subsequently, the sum of the values for all four airports was obtained. This process was repetitively performed by changing the stress scaling factor. The stress scaling factor for the least value of the squared difference in slab thicknesses was then calculated, as shown in Figure 8. A stress scaling factor of 0.827 was obtained for the maximum tensile stress predicted with the stress regression model developed in this study.

When the stress scaling factor of the fatigue model of $\mathrm{AC}$ $150 / 5320-6 \mathrm{E}(1 \cdot 13)$ was revised to $0 \cdot 827$, the allowable load repetitions were observed to increase, as shown in Figure 9.

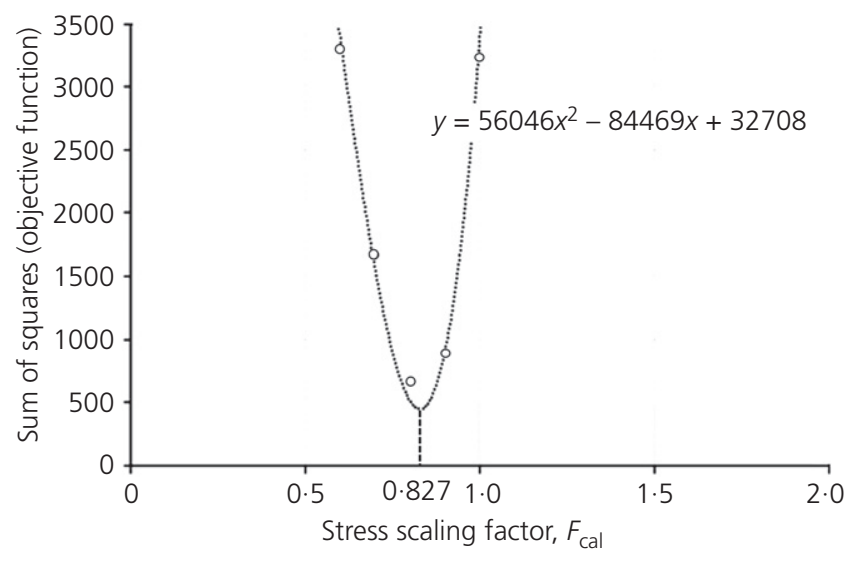

Figure 8. Correction of stress scaling factor by least-squares method

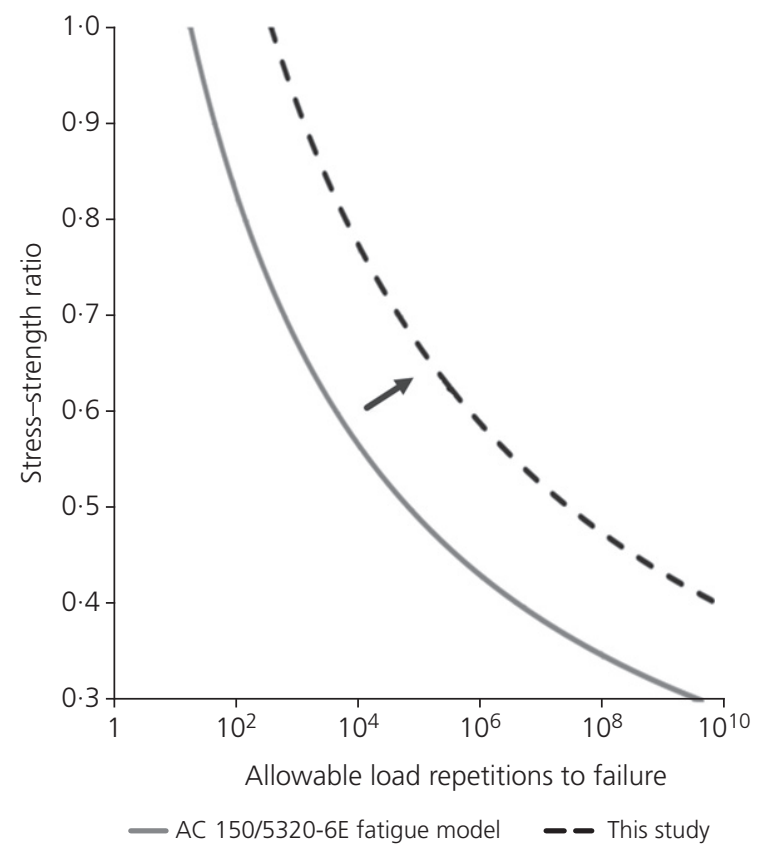

Figure 9. Change of allowable load repetition to failure by corrected stress scaling factor
The stress-strength ratio was observed to be greater when environmental and traffic loads were simultaneously applied compared to when only traffic loads were applied. Therefore, it was concluded that when the stress regression model developed in this study was used, it was reasonable for the stress-strength ratio needed to calculate the allowable load repetitions to be greater than that of AC 150/5320-6E. As a result, the fatigue model was corrected so that the same design lifespan as that of AC 150/5320-6E could be predicted when environmental and traffic loads were simultaneously considered (unlike existing design methods that only consider traffic loads).

\section{Application of the corrected fatigue model}

For the ACPs at Incheon international airport, Muan international airport, Cheongju international airport and Sacheon airport (Table 1 (Molit, 2014)), the slab thickness and joint spacing were redesigned using the stress regression model for the case of simultaneous application of environmental and traffic loads. The corrected fatigue model of AC 150/5320-6E was applied.

In previous studies, only the slab thickness was designed and joint spacing was determined empirically. However, in this study, the slab thickness and joint spacing were designed concurrently in a mechanistic manner. The slab thickness of each ACP was fixed as the actual slab thickness and the joint spacings as designed by the stress regression model proposed in this study and by the existing fatigue model were compared. Figure 10(a) shows that, by using the proposed model, the ACP joint spacings at Incheon international airport, Muan international airport and Cheongju international airport decreased from $6 \mathrm{~m}$ to $3.8 \mathrm{~m}, 4.75 \mathrm{~m}$ and $5.25 \mathrm{~m}$, respectively. On the contrary, the joint spacing of the ACP at Sacheon airport increased from $5.75 \mathrm{~m}$ to $7.6 \mathrm{~m}$. The joint spacing of the ACP was then fixed at the actual joint spacing for each airport and a comparison was made between the thickness of the slab designed with the stress regression model and the existing fatigue model. The results (Figure 10(b)) show that, with the proposed model, the slab thicknesses increased at Incheon (from the actual thickness of $500 \mathrm{~mm}$ to $640 \mathrm{~mm}$ ), Muan (from $400 \mathrm{~mm}$ to $440 \mathrm{~mm}$ ) and Cheongju (from $400 \mathrm{~mm}$ to $420 \mathrm{~mm}$ ). However, Sacheon airport's slab thickness decreased from an actual thickness of $380 \mathrm{~mm}$ to $340 \mathrm{~mm}$.

Thus, when environmental loads are considered in addition to traffic loads, slab thicknesses and joint spacings may need to be designed differently from the case when only the traffic loads are considered. This is due to the climatic conditions of the regions where the airports are located.

The relationships between slab thickness and joint spacing for slabs with a design lifespan of 20 years through simultaneous consideration of environmental and traffic loads are presented in Figure 11. As shown in the figure, Incheon international 


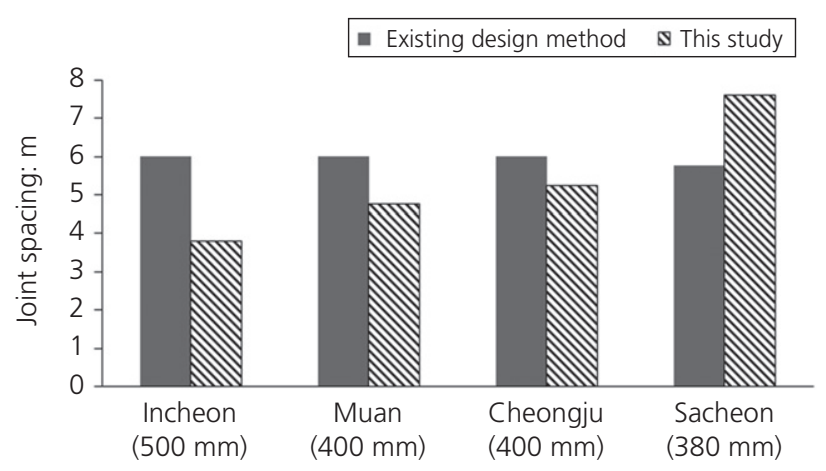

(a)

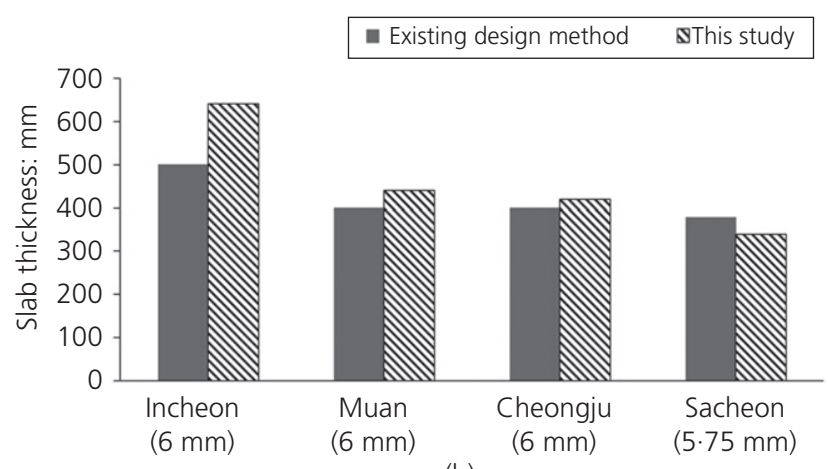

(b)

Figure 10. Comparison of results obtained from the existing design method and the proposed model: (a) joint spacing for fixed (actual) slab thickness; (b) slab thickness for fixed (actual) joint spacing

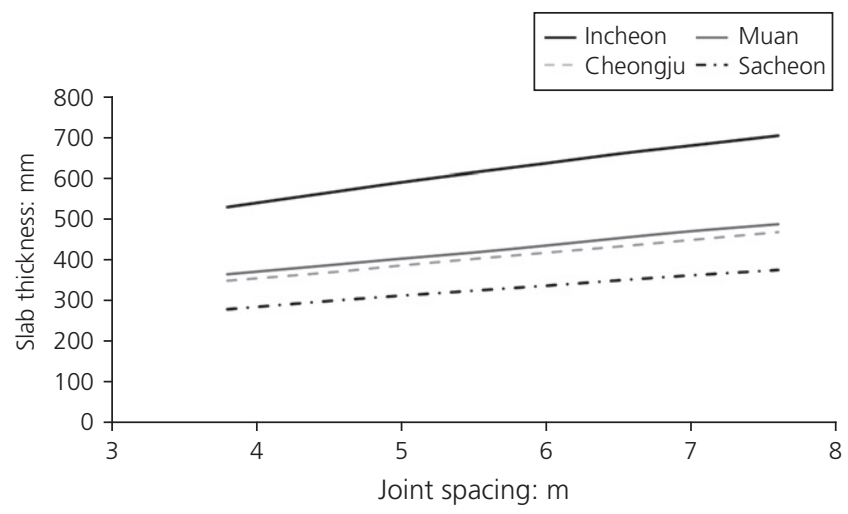

Figure 11. Slab thickness variation with joint spacing according to the results of this study

airport should have a slab thickness of $640 \mathrm{~mm}$ for a joint spacing of $6 \mathrm{~m}$ and a slab thickness of $590 \mathrm{~mm}$ for a joint spacing of $5 \mathrm{~m}$. For a joint spacing of $6 \mathrm{~m}$, Muan international airport, Cheongju international airport and Sacheon airport should have slab thicknesses of 440, 420 and $340 \mathrm{~mm}$, respectively, and slab thicknesses of 410, 390 and $320 \mathrm{~mm}$, respectively, for a joint spacing of $5 \mathrm{~m}$.

\section{Conclusions}

A method for the design of ACPs considering environmental loads as well as aeroplane gear loads has been presented. Information on the ACPs of existing airports where DDT gears were used for the design aircraft was collected. Under the simultaneous application of environmental and traffic loads, the resulting slab stresses were calculated using FeaFaa, an FEA program for airport pavements. In addition, a regression model for the maximum tensile stresses of ACP slabs was developed using the statistical analysis program SPSS. The maximum tensile stress calculated using the proposed stress regression model when environmental and traffic loads were simultaneously applied was found to be significantly different from the maximum tensile stress calculated using Westergaard's edge loading equation for traffic loads only. The fatigue model used in AC 150/5320-6E (FAA, 2009) was corrected for the maximum tensile stress to be appropriate for this study. A new stress scaling factor that minimises the difference between the actual slab thickness of an existing ACP and the thickness of a newly designed slab was found to replace the stress scaling factor of the fatigue model in AC 150/5320-6E. Using the stress regression model developed in this study and the corrected fatigue model, the slab thicknesses and joints spacings of existing ACPs were redesigned. The results showed that when environmental loads were considered, the slab thicknesses and joint spacings were different from designs only considering traffic loads. This is due to the meteorological conditions of the regions where the studied airports are located.

Until now, only slab thicknesses have been designed, with joint spacings empirically determined. However, the results of the current study enable a mechanistic design of joint spacings in tandem with slab thicknesses. In this study, using DDT gear as a design aircraft, under simultaneous environmental and traffic loads, a maximum tensile stress regression model of an ACP slab was developed and a stress scaling factor of the existing fatigue model was calculated. In the future, it is considered necessary to consider aircraft with different types of gears by applying aircraft conversion factors.

\section{Acknowledgement}

This work was supported by an Inha University research grant.

\section{REFERENCES}

Bazant ZP and Boweja S (1995) Creep and shrinkage prediction model for analysis and design of concrete structures - model B3. Materials and Structures 28(6): 357-365.

Bazant ZP and Panula L (1978) Practical prediction of time-dependent deformations of concrete, part 1, shrinkage; part 2, creep. Materials and Construction 11(5): 307-316.

Brill DR (2010) Calibration of FaarField Rigid Pavement Design Procedure. Federal Aviation Administration, US Department of Transportation, Washington, DC, USA.

Darter MI (1990) Concrete slab vs beam fatigue models. Proceedings of the 2nd International Workshop on the Theoretical Design of Concrete Pavement, Sigüenza, Spain, pp. 472-481. 
FAA (Federal Aviation Administration) (1995) AC 150/5320-6D: Standards for airport pavement design and evaluation. Office of Airport Safety and Standards, Federal Aviation Administration, US Department of Transportation, Washington, DC, USA

FAA (2009) AC 150/5320-6E: Standards for airport pavement design and evaluation. Office of Airport Safety and Standards, Federal Aviation Administration, US Department of Transportation, Washington, DC, USA.

Gardner NJ (2004) Comparison of prediction provisions for drying shrinkage and creep of normal-strength concretes. Canadian Journal of Civil Engineering 31(5): 767-775.

Hossain AB and Weiss J (2004) Assessing residual stress development and stress relaxation in restrained concrete ring specimens. Cement \& Concrete Composites 26(5): 531-540.

Jeong JH, Lim JS, Sun RJ and Zollinger DG (2012) Modelling of differential shrinkage for pavement design. Proceedings of the Institution of Civil Engineers - Transport 165(1): 3-14, https://doi.org/10.1680/tran.10.00020.

Kim SM (2007) Features of critical tensile stresses in jointed concrete pavement under environmental and vehicle loads. Journal of the Korea Concrete Institute 19(4): 449-456.

Kim YT (2014) Analysis of Stress in Airport Concrete Pavement Caused by Double Duals in Tandem Gear Loading. Master thesis, Inha University, Incheon, Korea.

Liu JH (2015) A Mechanistic Design Method for Airport Concrete Pavements Considering Environmental and Dual Tandem Gear Loads. PhD dissertation, Inha University, Incheon, Korea.

Mohamed AR and Hansen W (1997) Effect of nonlinear temperature gradient on curling stress in concrete pavement. Transportation Research Record 1568: 65-71.

Molit (Ministry of Land, Infrastructure and Transport) (2014) Development of Construction and Maintenance Technology for Low-Carbon Green Airport Pavements (2nd Phase). Molit, Sejong, Korea.

Packard RG (1974) Fatigue concepts for concrete airport pavement design. Transportation Engineering Journal, ASCE 100(3): 567-582.
Park JW, Jeong YD, Lim JS and Jeong JH (2009) A preliminary study on reduction of shrinkage stress in concrete slabs. International Journal of Highway Engineering 11(4): 87-94.

Park JY, Hong DS, Kim YT and Jeong JH (2013) Development of environmental load calculation method for airport concrete pavement design. Journal of the Korean Society of Civil Engineers 33(2): 729-737.

Park JY, Yeom WS, Kim SH and Jeong JH (2015) Environmental load for design of airport concrete pavement. Proceedings of the Institution of Civil Engineers - Transport 168(2): 139-149, https://doi.org/10.1680/tran.13.00007.

Rollings RS (1989) Developments in the Corps of Engineers rigid airfield design of airport concrete pavement. Proceedings of the 4th International Conference on Concrete Pavement Design and Rehabilitation, Purdue University, West Lafayette, IN, USA, pp. 405-418.

Rollings RS and Witczak M (1990) Structural deterioration model for rigid airfield pavements. Journal of Transportation Engineering 116(4): 479-491.

Thompson MR and Barenberg EJ (1992) NCHRP Project 1-26: Calibrated Mechanistic Structural Analysis Procedure for Pavements - Phase 2. Transportation Research Board, Washington, DC, USA.

Videla CC, Carreira DJ, McDonald DB and Gardner NJ (2008) ACI 209 2R-08: Guide for modeling and calculating shrinkage and creep in hardened concrete. ACI, Farmington Hills, MI, USA

Westergaard HH (1948) New formulas for stresses in concrete pavements of airfields. Transactions of the American Society of Civil Engineers 113(2340): 425-444.

Yang SC, Ahn NS, Choi DU and Kang SM (2004) Drying shrinkage of concretes according to different volume-surface ratios and aggregate types. Journal of Korean Society of Road Engineers 6(4): $519-524$.

Yu SK (2000) Pavement design of Incheon international airport. Journal of Korean Society of Road Engineers 2(2): 74-80.

\section{How can you contribute?}

To discuss this paper, please email up to 500 words to the editor at journals@ice.org.uk. Your contribution will be forwarded to the author(s) for a reply and, if considered appropriate by the editorial board, it will be published as discussion in a future issue of the journal.

Proceedings journals rely entirely on contributions from the civil engineering profession (and allied disciplines). Information about how to submit your paper online is available at www.icevirtuallibrary.com/page/authors, where you will also find detailed author guidelines. 